\title{
The global overlap of bioenergy and carbon sequestration potential
}

\author{
P. A. Turner ${ }^{1}$ • K. J. Mach $^{2}$ • D. B. Lobell ${ }^{2,3}$. \\ S. M. Benson ${ }^{4}$ E. Baik ${ }^{4}$ - D. L. Sanchez ${ }^{1}$ - C. B. Field ${ }^{5}$
}

Received: 10 November 2017 / Accepted: 18 March 2018 / Published online: 3 April 2018

(C) The Author(s) 2018

\begin{abstract}
Bioenergy with carbon capture and storage (BECCS) is a negative emissions technology that is a largely untested but prominent feature of ambitious climate change mitigation scenarios. This strategy involves capturing carbon dioxide $\left(\mathrm{CO}_{2}\right)$ from stationary bioenergy facilities and sequestering it in suitable geological formations, effectively removing $\mathrm{CO}_{2}$ from the atmosphere. Many factors potentially limit BECCS deployment including obstacles to building pipeline networks that move large quantities of liquefied $\mathrm{CO}_{2}$ over long distances. Here, we examine the BECCS opportunity that exists in regions overlapping storage basins. Under current conditions, the equivalent of $22.9 \mathrm{GtCO}_{2} \mathrm{y}^{-1}$ of net primary production (NPP), a measure of biomass growth, overlies highly prospective $\mathrm{CO}_{2}$ storage basins, representing a sustainably harvestable total of approximately $7.6 \mathrm{GtCO}_{2} \mathrm{y}^{-1}$. Most land overlying basins is either forested or linked to food production. If only marginal agricultural lands, those inconsistently under agricultural production, are used to source biomass, the scale of the available resource is approximately $1 \mathrm{GtCO}_{2} \mathrm{y}^{-1}$. If transportation of biomass or $\mathrm{CO}_{2}$ is constrained, and if BECCS is not developed on forests or prime croplands, then BECCS deployments will be limited to a small, but meaningful fraction $(\sim 10 \%)$ of the levels typical in costoptimized model trajectories that stabilize warming at $2{ }^{\circ} \mathrm{C}$ or less above pre-industrial temperatures. Marginal agricultural lands over storage basins can be an entry point for maturing the engineering technologies and financial markets needed for BECCS.
\end{abstract}

\section{P. A. Turner}

pturner@carnegiescience.edu

1 Department of Global Ecology, Carnegie Institution for Science, Stanford, CA 94305, USA

2 Department of Earth System Science, Stanford University, Stanford, CA 94305, USA

3 Center on Food Security and the Environment, Stanford University, Stanford, CA 94305, USA

4 Department of Energy Resources Engineering, Stanford University, Stanford, CA 94305, USA

5 Stanford Woods Institute for the Environment, Stanford University, Stanford, CA 94305, USA 


\section{Introduction}

Integrated assessment models (IAMs) that generate emission scenarios consistent with end-ofcentury warming well below $2{ }^{\circ} \mathrm{C}$ typically include extensive deployment of BECCS in leastcost scenarios (Clarke et al. 2014; Anderson and Peters 2016). The median removes more than $12 \mathrm{GtCO}_{2} \mathrm{y}^{-1}$ in 2100 (Smith et al. 2016), a quantity larger than the recent terrestrial or oceanic carbon sink (Fuss et al. 2014). While this level of BECCS appears to be cost-effective in stylized models, its feasibility and cost at scale are not well known. Estimates of costs, potential rates of deployment, and sustainable scales rely on extrapolations from disconnected biomass and $\mathrm{CO}_{2}$ injection industries, plus initial experience from a single ethanol-based BECCS demonstration plant with an estimated total capacity of $1 \mathrm{MtCO}_{2} \mathrm{y}^{-1}$ (Global CCS institute 2016).

Increasing the scale of BECCS deployment by several orders of magnitude will likely encounter a range of technical, economic, institutional, and social hurdles (Kemper 2015; Buck 2016). For some of these hurdles, the prospects for overcoming them are unclear, and it is useful to examine the potential scale of BECCS in the event that one or more of these barriers persists. One potentially important hurdle is the need for a low cost transport system. Ultimately, BECCS requires that the $\mathrm{CO}_{2}$ reach a suitable injection location. This could entail transporting biomass to an appropriately located BECCS facility overlying a storage site or moving $\mathrm{CO}_{2}$ to a suitable injection site. As a consequence of the low energy density of biomass, the latter option appears to be the cheaper one, and most mitigation scenarios rely on pipeline networks to move large quantities of supercritical $\mathrm{CO}_{2}$ from bioenergy point sources (i.e., bioelectric power plants, biorefineries) to suitable injection points (i.e., sinks) where $\mathrm{CO}_{2}$ storage is feasible (van Vuuren et al. 2010; Johnson et al. 2014; Koelbl et al. 2014). This pipeline infrastructure requires large capital investment and faces difficult-to-estimate implementation challenges, especially on a global scale where biomass sources and suitable injection formations may be in different countries. For instance, there is substantial potential for bioenergy in Japan and South Korea but little potential for geological $\mathrm{CO}_{2}$ storage (Kraxner et al. 2014a, b).

The construction of a widespread pipeline network, potentially much larger than the existing network of oil and gas pipelines (Fuss et al. 2016), is a major undertaking. Challenges include difficult terrain, permitting, and public concerns about safety. Additional biomass transport options, including ship, truck, or rail, may be viable in some settings, but with comparable or even greater challenges. Because $\mathrm{CO}_{2}$ transport impedes near-term deployments of BECCS, it is important to understand the potential scale of BECCS if deployments are limited to locations that overlie suitable injection sites. These sites are likely to present attractive near-term opportunities for developing the technologies and markets associated with BECCS, in addition to stimulating exploration of the issues surrounding transport infrastructure. We focus here on identifying the areas with potential for BECCS without the need for long-distance transport, and on estimating the total negative emissions that could be expected from these areas.

Additional biomass demands imply some combination of diverting biomass from agricultural lands into biomass product streams and converting non-agricultural lands to growing energy crops, including switchgrass, Miscanthus, or fast-growing woody species. The specifics of the combination and the quantity of biomass delivered are subject to a diverse suite of economic, regulatory, and biophysical constraints (Calvin et al. 2009). IAMs, to different extents, have explored several of these. Generally, they start from the assumption that 
landowners will select land use and levels of inputs that maximize profits, with specific scenarios addressing constraints that, for example, prevent conversion of food-producing areas to biomass or protect landscapes with high biodiversity (Popp et al. 2014). The conclusion from these simulations is that, even with land-use constraints, the global potential for biomass production is so high that carbon prices consistent with limiting warming to less than $2{ }^{\circ} \mathrm{C}$ lead to multigigaton deployment of BECCS over the next several decades.

Convenient access to suitable storage basins is only one of several possible constraints on BECCS deployment. Another is that not all land overlying storage basins is suitable for energy crops, and some areas will likely be priorities for carbon sequestration, food production, or biodiversity protection. As a technical upper bound, we allow the total conversion of existing vegetation types to energy crops. As a lower bound, we incorporate a wide range of possible exclusions and limit BECCS to existing croplands. Specifically, we define the lower bound as the sum of biomass from agricultural residues plus conversion of infrequently cropped agricultural lands to continuous energy crop cultivation. The potential opportunity for BECCS in a world with no new $\mathrm{CO}_{2}$ pipelines or long-distance biomass transport would likely fall within these bounds.

\section{Materials and methods}

Although there have been few detailed explorations of suitable $\mathrm{CO}_{2}$ storage basins at the global scale (Haszeldine 2006), it is widely known that sedimentary basins are best suited for $\mathrm{CO}_{2}$ storage (Benson and Cole 2008). Saline aquifers and oil and gas reservoirs, which are commonly considered $\mathrm{CO}_{2}$ storage resources, are co-located in sedimentary basins. The locations of major petroleum basins, which coincide with global sedimentary basins, are well known and have been used to provide the foundation for a qualitative, but coarse $\mathrm{CO}_{2}$ storage map (USGS 2001; Bradshaw and Dance 2005; Haszeldine 2006). Basins classified as "highly prospective" in Bradshaw and Dance (2005) are world class petroleum reservoirs with the right combination of depth, width, and geologic seals (Bradshaw and Dance 2005; IPCC 2005). For this study, we limit suitable storage to highly prospective basins (USGS 2001). Highly prospective basins have been used for regional BECCS assessments, including studies in Japan (Kraxner et al. 2014b) and South Korea (Kraxner et al. 2014a) and exploration of fossil fuel power plant source-to-sink disparities (Bradshaw and Dance 2005). Prospective storage regions that are delineated in Bradshaw and Dance (2005) indicate areas that have sedimentary basins that may not be fit for storage or are not well explored. The usage of only highly prospective storage basins captures the uncertainties that exist in some regions where basins have not been thoroughly explored or may not be ideal.

Net primary production (NPP) data from the Moderate Resolution Imaging Spectroradiometer (MODIS; 500-m spatial resolution) satellite were used to quantify the potential biomass resource. NPP is the annual above- and belowground biomass production of the actual vegetation. NPP of dedicated biomass crops might turn out to be higher or lower, but probably not by a large amount (Field et al. 2007). Estimating future NPP of energy crops from satellite-based estimates of current NPP is certainly not perfect, but it is attractive in providing a strong connection to observations and similar to several previous studies of potential NPP (Field et al. 2007; Krausmann et al. 2013).

The mean NPP over the available MODIS measurement period (2002-2014) was used to derive the spatially explicit distribution of biomass resources. To estimate a sustainably 
harvestable fraction to a first-approximation, we assume that $1 / 2$ of NPP is belowground and therefore not accessible for harvest (Frank et al. 2004; Field et al. 2007). We further assume that returning $1 / 3$ of aboveground NPP to the soil is sufficient for maintaining soil fertility. That leaves $2 / 3$ of aboveground NPP or $1 / 3$ of total NPP as the sustainably harvestable fraction. In practice, the quantity of organic matter needed to maintain soil fertility will vary depending on climate, vegetation, and soil type. Overlying storage information with MODIS derived land use and photosynthetic activity can therefore determine the readily available resource and identify potential strategic near-term locations for BECCS development.

Because marginal lands are dynamic and often described qualitatively (Kang et al. 2013), they are not a distinctive land class. We defined marginal agricultural land as land that is not cropped every year but is brought in and out of production with fluctuating commodity prices. Specifically, we counted the number of years MODIS classified a pixel as cropland from 2001 to 2014 (Friedl et al. 2010). If it was less than 11, we classified that location as marginal. This categorization implies that lands are accessible to energy crop cultivation and that an agricultural supply chain exists in the area.

National emission inventories excluding land-use change were downloaded from the Climate Analysis Indicators Tool (CAIT) from the World Resource Institute (http://cait.wri. org/). All data were processed using Google Earth Engine and Matlab.

\section{Results and discussion}

From 2002 to 2014, the total global terrestrial NPP was, on average, $212.6 \mathrm{GtCO}_{2} \mathrm{y}^{-1}$, a value that is in agreement with others (Field et al. 2007). If we assume that $50 \%$ of the NPP is allocated aboveground (Frank et al. 2004) and that 2/3 of the aboveground resource can be harvested sustainably to maintain soil carbon, then the sustainably harvestable biomass resource across the terrestrial biosphere is roughly $70.9 \mathrm{GtCO}_{2} \mathrm{y}^{-1}$ globally (Table 1).

Highly prospective $\mathrm{CO}_{2}$ basins underlie 1786 Mha of the terrestrial surface, but much of this area corresponds to relatively low NPP (Fig. 1). Notably, there are few high confidence storage basins under intensively cultivated regions, such as the United States Corn Belt or the Eurasian Wheat Belt, and there is an almost total lack of highly prospective storage under the equatorial forests of Africa and South America. Total NPP over the highly prospective basins is $22.9 \mathrm{GtCO}_{2} \mathrm{y}^{-1}$, corresponding to a sustainably harvestable total of $7.6 \mathrm{GtCO}_{2} \mathrm{y}^{-1}$ or $11 \%$ of the global quantity (70.9 $\left.\mathrm{GtCO}_{2} \mathrm{y}^{-1}\right)$.

Future energy crops will need to displace natural and managed ecosystems, and biodiversity protection and food production should be considered. To better understand these constraints, we estimate the maximum potential production of sustainably harvested biomass overlying suitable storage formations for each vegetation type based on the assumption that current NPP is a useful proxy for energy crop NPP (Fig. 2). These estimates represent an upper bound for each land-use type.

Evergreen broadleaf forests are the most productive vegetation class, leading to a total sustainably harvestable resource of $1.3 \mathrm{GtCO}_{2} \mathrm{y}^{-1}$ grown on $103 \mathrm{Mha}$, largely in Peru, Colombia, and Indonesia. Other productive vegetation types that substantially overlap highly prospective basins include cropland/natural vegetation mosaic, deciduous broadleaf forest, savannas, and mixed forest. Though croplands are the largest readily available resource and could sustainably contribute up to $1.5 \mathrm{GtCO}_{2} \mathrm{y}^{-1}$, relatively low sustainable harvests imply the requirement for a large land area. 
Table 1 The NPP and area by land-use type for global and overlying basin totals. Data used in Fig. 2 describe the potentially harvestable NPP and area over basins

\begin{tabular}{|c|c|c|c|c|c|c|}
\hline \multirow[b]{2}{*}{ Vegetation type } & \multicolumn{2}{|l|}{ Area } & \multicolumn{2}{|l|}{ Total NPP } & \multicolumn{2}{|c|}{ Potentially harvestable NPP } \\
\hline & $\begin{array}{l}\text { Global } \\
\text { (Mha) }\end{array}$ & $\begin{array}{l}\text { Over basins } \\
\text { (Mha) }\end{array}$ & $\begin{array}{l}\text { Global } \\
\left(\mathrm{GtCO}_{2} \mathrm{y}^{-1}\right)\end{array}$ & $\begin{array}{l}\text { Over basins } \\
\left(\mathrm{GtCO}_{2} \mathrm{y}^{-1}\right)\end{array}$ & $\begin{array}{l}\text { Global } \\
\left(\mathrm{GtCO}_{2} \mathrm{y}^{-1}\right)\end{array}$ & $\begin{array}{l}\text { Over basins } \\
\left(\mathrm{GtCO}_{2} \mathrm{y}^{-1}\right)\end{array}$ \\
\hline $\begin{array}{l}\text { Evergreen Broadleaf } \\
\text { forest }\end{array}$ & 1320.0 & 102.7 & 52.5 & 4.0 & 17.5 & 1.3 \\
\hline $\begin{array}{l}\text { Cropland/Natural } \\
\text { vegetation mosaic }\end{array}$ & 844.0 & 120.8 & 20.3 & 3.0 & 6.8 & 1.0 \\
\hline $\begin{array}{l}\text { Deciduous Broadleaf } \\
\text { forest }\end{array}$ & 153.0 & 53.9 & 3.9 & 1.3 & 1.3 & 0.4 \\
\hline Savannas & 903.0 & 25.1 & 22.4 & 0.6 & 7.5 & 0.2 \\
\hline Mixed forest & 894.0 & 136.9 & 22.8 & 3.1 & 7.6 & 1.0 \\
\hline Closed shrublands & 24.6 & 1.9 & 0.4 & $<0.1$ & 0.1 & $<0.1$ \\
\hline $\begin{array}{l}\text { Evergreen Needleleaf } \\
\text { forest }\end{array}$ & 385.0 & 65.9 & 7.2 & 1.2 & 2.4 & 0.4 \\
\hline Woody savannas & 1090.0 & 77.5 & 27.7 & 1.4 & 9.2 & 0.5 \\
\hline Croplands & 1200.0 & 262.3 & 23.3 & 4.6 & 7.8 & 1.5 \\
\hline $\begin{array}{l}\text { Deciduous Needleleaf } \\
\text { forest }\end{array}$ & 176.0 & 36.3 & 2.3 & 0.5 & 0.8 & 0.2 \\
\hline Grasslands & 1850.0 & 257.6 & 18.2 & 2.5 & 6.1 & 0.8 \\
\hline Permanent wetlands & 145.0 & 44.7 & 0.9 & 0.2 & 0.3 & 0.1 \\
\hline Urban and built-up & 64.2 & 13.8 & $<0.1$ & $<0.1$ & $<0.1$ & $<0.1$ \\
\hline Open shrublands & 1980.0 & 177.7 & 10.7 & 0.4 & 3.6 & 0.1 \\
\hline Snow and ice & 376.0 & 2.2 & $<0.1$ & $<0.1$ & $<0.1$ & $<0.1$ \\
\hline $\begin{array}{l}\text { Barren or sparsely } \\
\text { vegetated }\end{array}$ & 1860.0 & 407.3 & 0.2 & $<0.1$ & 0.1 & $<0.1$ \\
\hline
\end{tabular}

Because BECCS will be more valuable for $\mathrm{CO}_{2}$ removal rather than as a source of energy (Klein et al. 2014; Sanchez et al. 2015), it will rarely make sense to replace forests, a high carbon value ecosystem, with energy crops. Though the economics might be compelling, unless the initial harvest, prior to energy crop deployment, is utilized for biomass energy, the carbon debt from deforestation is a large setback, difficult to reverse even after decades of management for biomass crops (Fargione et al. 2008). High carbon value ecosystems are often protected in IAMs for this reason, and some models rely on afforestation as a cost-effective



Fig. 1 Source-to-sink BECCS capacity matching. The total sustainably harvestable NPP resource is estimated from the average 13-y MODIS NPP ( $\mathrm{kg} \mathrm{CO}_{2} \mathrm{~m}^{-2} \mathrm{y}^{-1}$; green). Marginal lands (magenta) describe agricultural lands that are intermittently cultivated over the MODIS land classification period. Highly prospective $\mathrm{CO}_{2}$ storage basins are indicated as gray polygons 


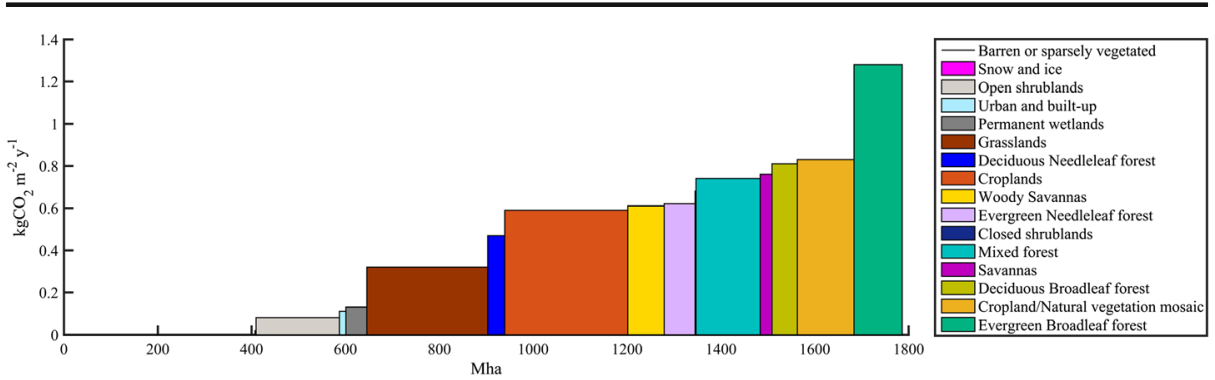

Fig. 2 A global $\mathrm{CO}_{2}$ land resource supply curve of land cover types overlying highly prospective $\mathrm{CO}_{2}$ storage basins. The area of each bar represents the sustainably harvestable negative emission potential, while the $y$-axis denotes removal efficiency

carbon removal technology (Popp et al. 2014; Griscom et al. 2017). Forested lands account for $52 \%$ of the sustainably harvestable NPP over highly prospective basins $\left(4 \mathrm{GtCO}_{2} \mathrm{y}^{-1}\right.$; Fig. 3). As a group, forested lands are the most photosynthetically productive. However, the carbon relevance of currently forested lands in producing BECCS feedstocks is likely to depend on (1) whether policies require accounting for the deforestation-related carbon debt and (2) whether the BECCS technology allows utilization of the initial (pre-energy crop) biomass for energy.

More than one third (36\%) of the total area overlying basins is either unsuitable for agriculture (e.g., urban or wetlands) or has NPP so low that commercial harvesting is unlikely to be economically viable (e.g., frozen, desert, or shrubland). Though vast (647 Mha), these
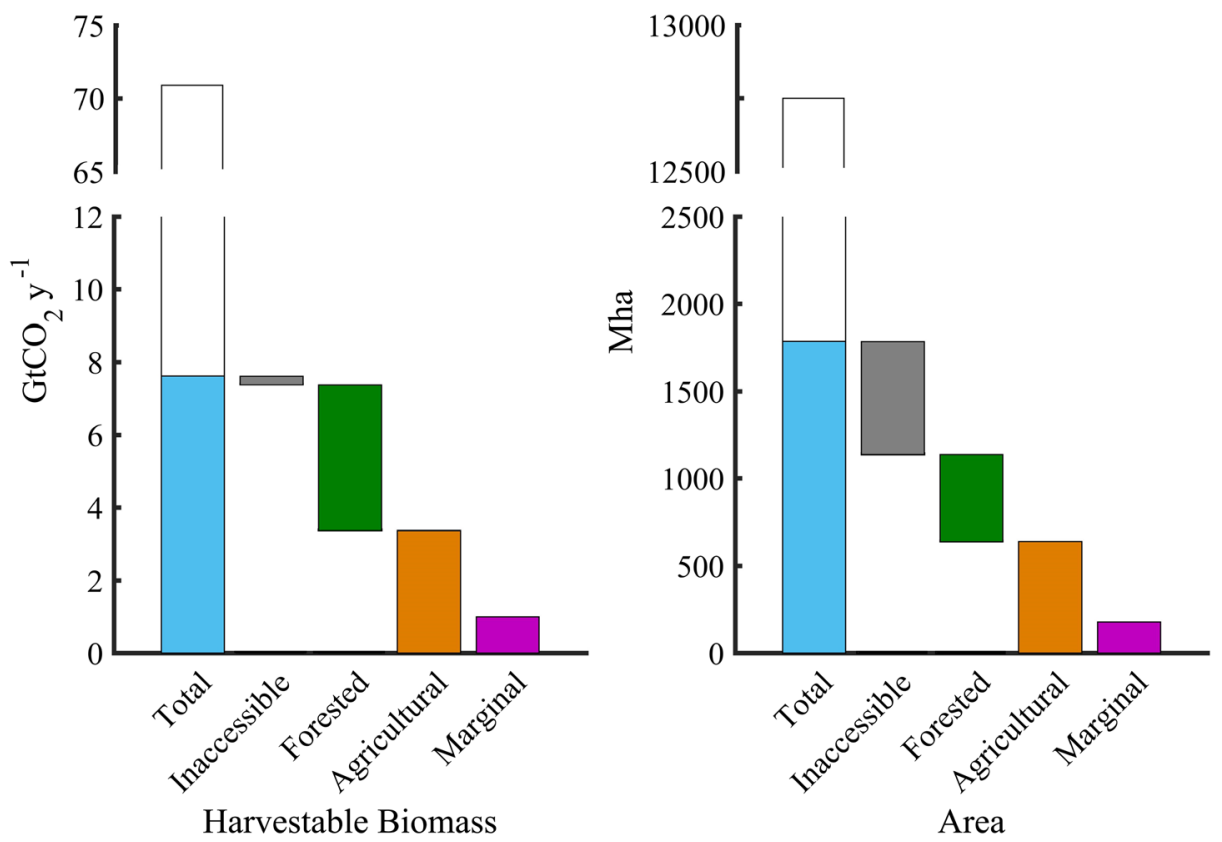

Fig. 3 A disaggregation of the total sustainably harvestable biomass resource and area overlying basins (blue). Land-use types were aggregated and include inaccessible (urban and built-up, barren or sparsely vegetated, open and closed shrublands, permanent wetlands, and snow and ice), forested (evergreen broadleaf forest, mixed forest, deciduous broadleaf forest, evergreen needleleaf forest, deciduous needleleaf forest, savannas, and woody savannas), and agricultural (croplands, cropland/natural vegetation mosaic, and grasslands) 
lands produce a total NPP of only $0.6 \mathrm{GtCO}_{2} \mathrm{y}^{-1}$ or a sustainably harvestable level of 0.2 $\mathrm{GtCO}_{2} \mathrm{y}^{-1}$ (Fig. 3). Some of these areas, regions in North Africa and the Middle East for instance, with ample solar and basin capacity but negligible NPP could represent important areas for direct air capture deployment.

Croplands and grasslands constitute the remaining $10.2 \mathrm{GtCO}_{2} \mathrm{y}^{-1}$ of NPP or 3.4 $\mathrm{GtCO}_{2} \mathrm{y}^{-1}$ of sustainably harvestable biomass overlying a storage site, occupying 641 Mha of land (Fig. 3). Although this resource opportunity is approximately equivalent to a stabilization wedge (3.7 $\left.\mathrm{GtCO}_{2}\right)$ (Pacala and Socolow 2008), some of the area will be required for food production (food crops + livestock pasture). The acreage of cropland over basins (262 Mha) represents one fifth of the global cropland area. If these lands continue to be used for food production, the sustainably available material for bioenergy will be some fraction of the agricultural residues left after harvest. If $50 \%$ of aboveground NPP is allocated to harvestable material (grain) and 33\% must remain to maintain soil fertility, then the remaining $17 \%$ of aboveground NPP is available as residue. Under these assumptions, cropland residues could sustainably contribute $0.4 \mathrm{GtCO}_{2} \mathrm{y}^{-1}$ of BECCS.

Agricultural lands that are not cropped every year may be an attractive target for conversion to energy crops, since they are of limited value for food production. Marginal agricultural lands can be marginal for a number of reasons (Robertson et al. 2017). Building from farmer decisions about cropping, we define land as marginal if it is used for crop production in fewer than 11 years of the 13-year MODIS record. Based on this definition, the total NPP on marginal agricultural land over highly prospective basins is $3.4 \mathrm{GtCO}_{2} \mathrm{y}^{-1}$, with $1.1 \mathrm{GtCO}_{2}$ $\mathrm{y}^{-1}$ sustainably harvestable (Fig. 3).

Although $1.1 \mathrm{GtCO}_{2} \mathrm{y}^{-1}$ is approximately $10 \%$ of the supply used in $<2{ }^{\circ} \mathrm{C}$ scenarios, this is a meaningful first step towards decarbonization and, with carbon prices exceeding $\$ 100$ $\mathrm{tCO}_{2}{ }^{-1}$, represents a massive market opportunity. However, this is a conservative estimate because we implicitly target least-cost options with low implementation barriers, without the need to first develop a pipeline or other transportation networks. At low $\mathrm{CO}_{2}$ prices such opportunities could catalyze the development of the infrastructure and finance markets needed to meet $<2{ }^{\circ} \mathrm{C}$ scenario targets. Going beyond the BECCS potentials presented here will require long distance travel, and techno-economic analyses at different price points are needed to understand how the potential harvestable resource changes with respect to $\mathrm{CO}_{2}$ price. Yield improvements and energy transformations, such as those included in IAM scenarios, are likely to increase the potential as well.

The intersection of storage basins and agricultural land not cropped continuously is concentrated in a few regions. North America dominates at the continental scale as consequence of widespread storage potential in both the USA and Canada. Australia, Africa, Asia, and South America do not have extensive highly prospective basins (Fig. 4a).

At the national scale, over half $(51 \%)$ of the sustainably harvestable biomass from marginal agricultural lands is situated in three countries: the USA $\left(0.3 \mathrm{GtCO}_{2} \mathrm{y}^{-1}\right)$, Russia $\left(0.13 \mathrm{GtCO}_{2}\right.$ $\left.\mathrm{y}^{-1}\right)$, and Canada $\left(0.1 \mathrm{GtCO}_{2} \mathrm{y}^{-1}\right)$. More than three quarters of the resource is in 10 countries (the USA, Russia, China, Canada, Myanmar, Mexico, Indonesia, Romania, Germany, and Venezuela) (Fig. 4b). Although these estimates are small relative to global emissions, they could help allow select countries to meet ambitious decarbonization targets. In Myanmar and Hungary for example, as much as 58 and $24 \%$ of recent national emissions, respectively, could be offset using the sustainably harvestable biomass from marginal agricultural lands for BECCS. 

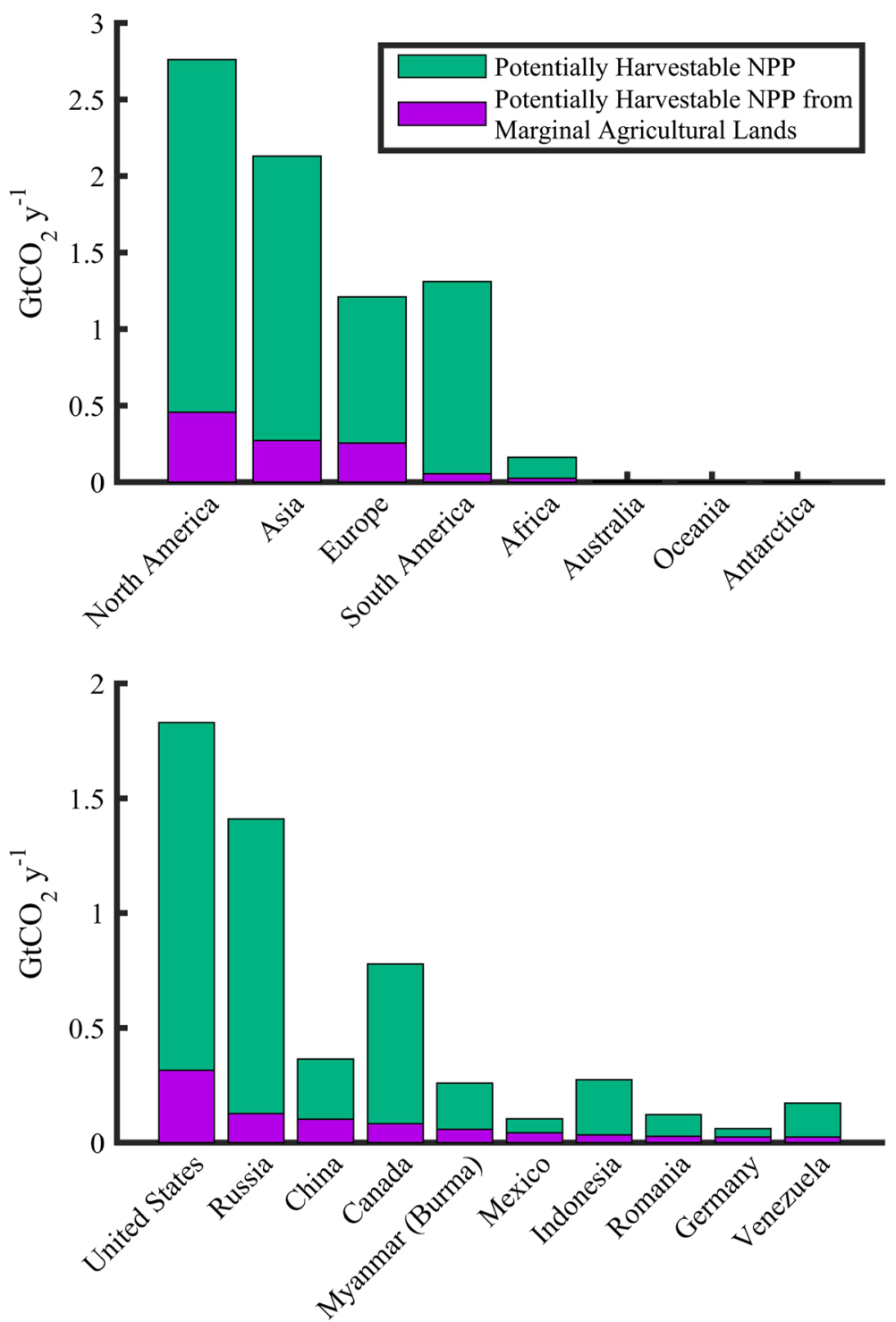

Fig. 4 The total sustainably harvestable resource (green) and the total sustainably harvestable resource from marginal lands (magenta) overlying highly prospective $\mathrm{CO}_{2}$ storage basins. Sorted in decreasing order of potential on marginal lands (magenta)

These estimates are based on one approach to estimating the sustainably harvestable biomass resource. Three main factors could increase or decrease the amount of available biomass co-located with suitable storage basins. First, the area of suitable storage basins may change. Storage in igneous rocks such as basalt may be possible, as demonstrated in Iceland (Matter et al. 2016). In this case, the land area for highly prospective sites would increase dramatically, for example, in India. Storage basins in some regions (e.g., Central Africa) are not well explored, and injection into low to moderate prospectivity basins may be practical in some cases because the low energy density of biomass and limited collection area for an 
individual project results in relatively small emissions sources, requiring only marginal storage capacity and injectivity. Second, future NPP of biomass crops may be higher or lower than recent NPP. Typically, the conversion of native vegetation to agriculture reduces NPP, largely because annual crops have a shorter growing period (Krausmann et al. 2013). Though perennial energy crops may be impacted less by the length of the growing season, other factors, including the time needed for crop improvement and limited farmer experience, are likely to be constraints (Field et al. 2007). Subsidies in the form of fertilizer or especially irrigation can push the NPP of managed land well above those of unmanaged ecosystems (Krausmann et al. 2013). Such subsidies would increase biomass for BECCS but would also increase costs. Subsidies and improved management would have the greatest NPP impact in regions where the yield gap is largest, in developing countries and marginal lands for instance. Higher $\mathrm{CO}_{2}$ concentrations, climate change, crop selection, or crop improvement could all lead to increased NPP, although climate change and crop selection could also lead to decreased NPP. Third, the sustainably harvestable fraction of NPP could be more than $1 / 3$ in some settings and less in others.

The future success of BECCS depends on strategic plant siting to build up the necessary technology, infrastructure, and markets to support the nascent industry. Although the BECCS opportunity on marginal lands overlying storage basins is substantially less than ambitious climate stabilization scenarios require, it is vastly greater than current $\mathrm{CO}_{2}$ removal and could, in turn, catalyze the development of the transport infrastructure needed to meet long-term climate targets.

Authors' contribution P.A.T., K.J.M., D.B.L., S.M.B., E.B., D.L.S., and C.B.F. conceptualized analysis and contributed feedback. P.A.T. analyzed data. P.A.T. drafted manuscript with K.J.M. and C.B.F. with edits from all authors.Funding informationThis work was funded by the David and Lucile Packard Foundation and the Alexander von Humboldt Foundation.

\section{Compliance with ethical standards}

Conflict of interest The authors declare that they have no conflict of interest.

Open Access This article is distributed under the terms of the Creative Commons Attribution 4.0 International License (http://creativecommons.org/licenses/by/4.0/), which permits unrestricted use, distribution, and reproduction in any medium, provided you give appropriate credit to the original author(s) and the source, provide a link to the Creative Commons license, and indicate if changes were made.

\section{References}

Anderson K, Peters G (2016) The trouble with negative emissions. Science 354:182-183

Benson SM, Cole DR (2008) CO2 sequestration in deep sedimentary formations. Elements 4:325-331. https://doi.org/10.2113/gselements.4.5.325

Bradshaw J, Dance T (2005) Mapping geological storage prospectivity of CO2 for the world sedimentary basins and regional source to sink matching. In: Proceedings of the 7th International Conference on Greenhouse Gas Control Technologies (GHGT-7). Vancouver, pp 583-592

Buck HJ (2016) Rapid scale-up of negative emissions technologies: social barriers and social implications. Clim Chang 139:155-167. https://doi.org/10.1007/s10584-016-1770-6

Calvin K, Edmonds J, Bond-lamberty B et al (2009) 2.6: limiting climate change to 450 ppm CO 2 equivalent in the 21st century. Energy Econ 31:S107-S120. https://doi.org/10.1016/j.eneco.2009.06.006

Clarke L, Jiang K, Akimoto K et al (2014) Assessing transformation pathways. Cambridge University Press, Cambridge 
Fargione J, Hill J, Tilman D et al (2008) Land clearing and the biofuel carbon debt. Science 319:1235-1237. https://doi.org/10.1126/science.1200609

Field CB, Campbell JE, Lobell DB (2007) Biomass energy: the scale of the potential resource. Trends Ecol Evol 23:65-72. https://doi.org/10.1016/j.tree.2007.12.001

Frank A, Berdahl J, Hanson J (2004) Biomass and carbon partitioning in switchgrass. Crop Sci 1396:1391-1396

Friedl MA, Sulla-menashe D, Tan B et al (2010) Remote sensing of environment MODIS collection 5 global land cover: algorithm refinements and characterization of new datasets. Remote Sens Environ 114:168-182. https://doi.org/10.1016/j.rse.2009.08.016

Fuss S, Canadell JG, Peters GP et al (2014) Betting on negative emissions. Nat Clim Chang 4:850-853. https://doi.org/10.1038/nclimate2392

Fuss S, Jones CD, Kraxner F et al (2016) Research priorities for negative emissions. Environ Res Lett 11:11. https://doi.org/10.1088/1748-9326/11/11/115007

Global CCS institute (2016) The Global Status of CCS: Summary Report

Griscom BW, Adams J, Ellis PW et al (2017) Natural climate solutions. Proc Natl Acad Sci 114:1-6. https://doi. org/10.1073/pnas.1710465114

Haszeldine RS (2006) Deep geological CO2 storage: principles reviewed, and prospecting for bio-energy disposal sites. Mitig Adapt Strateg Glob Chang 11:377-401. https://doi.org/10.1007/s11027-005-9005-6

IPCC (2005) IPCC special report on carbon dioxide capture and storage. Cambridge University Press, Cambridge

Johnson N, Parker N, Ogden J (2014) How negative can biofuels with CCS take us and at what cost? Refining the economic potential of biofuel production with CCS using spatially-explicit modeling. Energy Procedia 63:6770-6791. https://doi.org/10.1016/j.egypro.2014.11.712

Kang S, Post WM, Nichols JA et al (2013) Marginal lands: concept, assessment and management. J Agric Sci 5: 129-139. https://doi.org/10.5539/jas.v5n5p129

Kemper J (2015) Biomass and carbon dioxide capture and storage: a review. Int J Greenhouse Gas Control 40: 401-430. https://doi.org/10.1016/j.ijggc.2015.06.012

Klein D, Luderer G, Kriegler E et al (2014) The value of bioenergy in low stabilization scenarios: an assessment using REMIND-MAgPIE. Clim Chang 123:705-718. https://doi.org/10.1007/s10584-013-0940-z

Koelbl BS, van den Broek MA, Faaij APC, van Vuuren DP (2014) Uncertainty in carbon capture and storage (CCS) deployment projections: a cross-model comparison exercise. Clim Chang 123:461-476. https://oi. org/10.1007/s10584-013-1050-7

Krausmann F, Erb K-H, Gingrich S et al (2013) Global human appropriation of net primary production doubled in the 20th century. Proc Natl Acad Sci 110:10324-10329. https://doi.org/10.1073/pnas.1211349110

Kraxner F, Aoki K, Leduc S et al (2014a) BECCS in South Korea-analyzing the negative emissions potential of bioenergy as a mitigation tool. Renew Energy 61:102-108. https://doi.org/10.1016/j.renene.2012.09.064

Kraxner F, Leduc S, Fuss S et al (2014b) Energy resilient solutions for Japan - a BECCS case study. Energy Procedia 61:2791-2796. https://doi.org/10.1016/j.egypro.2014.12.316

Matter JM, Stute M, Snaebjornsdotter SO et al (2016) Rapid carbon mineralization for permanent disposal of anthropogenic carbon dioxide emissions. Science 352:1312-1314

Pacala S, Socolow R (2008) Stabilization wedges: solving the climate problem for the next 50 years with current technologies. Science 305:968-972. https://doi.org/10.1126/science.1100103

Popp A, Rose SK, Calvin K et al (2014) Land-use transition for bioenergy and climate stabilization: model comparison of drivers, impacts and interactions with other land use based mitigation options. Clim Chang 123:495-509. https://doi.org/10.1007/s10584-013-0926-x

Robertson GP, Hamilton SK, Barham BL et al (2017) Cellulosic biofuel contributions to a sustainable energy future: choices and outcomes. Science 356. https://doi.org/10.1126/science.aal2324

Sanchez DL, Nelson JH, Johnston J et al (2015) Biomass enables the transition to a carbon-negative power system across western North America. Nat Clim Chang:3-7. https://doi.org/10.1038/NCLIMATE2488

Smith P, Davis SJ, Creutzig F et al (2016) Biophysical and economic limits to negative CO2 emissions. Nat Clim Chang 6:42-50. https://doi.org/10.1038/nclimate2870〈rhttp://www.nature.com/nclimate/journal/v6/n1/abs/ nclimate2870.html\#supplementary-information

USGS (2001) U.S. geological survey world petroleum assessment 2000 - description and results, DDS-60

van Vuuren DP, Stehfest E, den Elzen MGJ et al (2010) Exploring IMAGE model scenarios that keep greenhouse gas radiative forcing below $3 \mathrm{~W} / \mathrm{m} 2$ in 2100. Energy Econ 32:1105-1120. https://doi.org/10.1016/j. eneco.2010.03.001 